TITLE:

\title{
Simultaneous enhancement in porosity and magnetic property of Fe-dispersing single-walled carbon nanohorns by oxidation using $\mathrm{CO} 2$
}

\section{AUTHOR(S):}

Sano, Noriaki; Himara, Daisuke; Tamon, Hajime

\section{CITATION:}

Sano, Noriaki ...[et al]. Simultaneous enhancement in porosity and magnetic property of Fe-dispersing single-walled carbon nanohorns by oxidation using CO2. Chemical

Engineering Journal 2015, 271: 43-49

\section{ISSUE DATE:}

2015-07

URL:

http://hdl.handle.net/2433/202625

\section{RIGHT:}

(c) 2015. This manuscript version is made available under the CC-BY-NC-ND 4.0 license

http://creativecommons.org/licenses/by-nc-nd/4.0/; The full-text file will be made open to the public on $1 \mathrm{July} 2017$ in accordance with publisher's 'Terms and Conditions for Self-Archiving'.; この論文は出版社版でありません。引用の際に は出版社版をご確認ご利用ください。; This is not the published version. Please cite only the published version. 


\title{
Simultaneous enhancement in porosity and magnetic property of Fe-dispersing single- walled carbon nanohorns by oxidation using $\mathrm{CO}_{2}$
}

Noriaki Sano*, Daisuke Himara, Hajime Tamon

Department of Chemical Engineering, Graduate School of Engineering,

Kyoto University, Nishikyo-ku, Kyoto 615-8510, Japan

\begin{abstract}
It was discovered that the specific surface area and magnetic susceptibility of Fe-dispersing single-walled carbon nanohorns (Fe-CNHs) were significantly increased without obvious destruction of $\mathrm{CNH}$ structures by oxidation in $\mathrm{CO}_{2}(10 \%)$ diluted with $\mathrm{N}_{2}$ at $1000{ }^{\circ} \mathrm{C}$. As-grown Fe-CNHs synthesized by a submerged arc discharge method had a specific surface area of 184 $\mathrm{m}^{2} / \mathrm{g}$, and this surface area was raised to $500 \mathrm{~m}^{2} / \mathrm{g}$ by opening of pores upon this oxidation treatment. Under this condition, the carbon-based specific surface area are enhanced from 211 $\mathrm{m}^{2} / \mathrm{g}$ to $863 \mathrm{~m}^{2} / \mathrm{g}$. Fe nanoparticles dispersing in Fe-CNHs were transformed into ferrimagnetic $\mathrm{Fe}_{3} \mathrm{O}_{4}$ nanoparticles without obvious change in their particle sizes and frames of CNHs. The magnetic susceptibility of the Fe-CNHs was increased by this oxidation, suggesting that their magnetic mobility could be improved. The structure of Fe-CNHs was stable against the extended oxidation duration in the $\mathrm{CO}_{2}-\mathrm{N}_{2}$. In contrast to the oxidation in $\mathrm{CO}_{2}-\mathrm{N}_{2}$, the oxidation in air resulted in the transformation of Fe nanoparticles into paramagnetic $\mathrm{Fe}_{2} \mathrm{O}_{3}$, and the excessive oxidation led to destructive loss of CNHs.
\end{abstract}

\footnotetext{
* Corresponding author. Tel: +81 75383 2684; fax: +81 75383 2654. E-mail address: sano@cheme.kyoto-u.ac.jp (N. Sano)
} 


\section{Introduction}

Carbon-nanotube (CNT) family materials have been widely studied, and their superior performances can be found in a broad range of applications including micro-sized electric circuit $[1,2]$, chemical and physical sensors [3,4], catalysts [5,6], gas energy storage [7,8], and so forth. Among those novel functional materials that have been explored, single-walled carbon nanohorns (CNHs) [9] are considered to be the materials that can exhibit useful chemical and physical properties. The structures of CNHs are regarded as the aggregated forms of single-walled closed horns, and it is widely known that a well-controlled oxidation in air can enlarge their specific surface area $[10,11]$ and produce suitable structures for drug delivery applications by opening their pores [12]. Mass production of CNHs can be achieved by evaporation of graphite using highpower laser $[13,14]$ or arc discharge [15-18]. In addition to the oxidation, which serves as a posttreatment procedure $[10,19]$, admixing metallic components in the fabrication step can improve the performance of CNHs, and CNHs dispersed with metallic nanoparticles can be obtained in this way [20,21]. Given the well-ground research basis, one may expect the novel functional materials to be fabricated by combining all these techniques together.

Aiming at investigating the diverse post-treatment conditions for developing new functional materials, this study focused on the mild oxidation of Fe-dispersing CNHs (Fe-CNHs) in $\mathrm{CO}_{2}-\mathrm{N}_{2}$ mixture instead of the conventional oxidation in air. As one of potential applications of the materials developed in this study, it can be considered that they can be useful to create new catalyst support for many reactions because porous and magnetic Fe-CNHs can supply amphiphilic surfaces by hybridizing hydrophobic carbon and hydrophilic Fe. In addition, when Fe in Fe-CNHs is oxidized to form magnetite $\mathrm{Fe}_{3} \mathrm{O}_{4}$, it could be used for application to produce biodiesels [5]. Furthermore, it was expected that the magnetic property of Fe could contribute to the magnetically driven micro- and nano-systems using synthesized Fe-CNHs, and by enhancing the porosity, their applications can also be expanded to potential new research topics. 


\section{Experimental}

CNHs were synthesized by a gas-injected arc-in-water (GI-AIW) method, and a detailed description of this method is reported elsewhere $[18,19]$. In brief, a graphite rod with a co-axially drilled hole was submerged in water acting as a cathode, and another piece of narrow graphite rod is used as an anode, where arc discharge is generated between these two electrodes. At the cathode, $\mathrm{N}_{2}$ was injected to realize a rapid quenching of vaporized carbon in $\mathrm{N}_{2}$ enriched atmosphere. The as-grown CNHs can be then collected in powder form floating on the water surface.

A modified GI-AIW method was used to synthesize Fe-CNHs [20,21] and the dimensions of the electrodes are summarized in Fig. 1 . In our study, a $60 \mathrm{~mm}$ deep hole with $1 \mathrm{~mm}$ diameter was co-axially drilled into the anode with a diameter of $3 \mathrm{~mm}$. Three pieces of Fe wires with diameter of $0.3 \mathrm{~mm}$ and length of $60 \mathrm{~mm}$ were inserted into the hole when the arc discharge was generated at discharge current of $80 \mathrm{~A}$ and DC voltage of $40 \mathrm{~V}$. The anode was then shifted at a constant speed of $2.2 \mathrm{~mm} \mathrm{~s}^{-1}$ to sustain the arc discharge, while Fe and carbon were simultaneously evaporated by the arc discharge, and Fe-CNHs can be synthesized by their co-condensation.

The oxidations of as-grown Fe-CNHs in both $\mathrm{CO}_{2}-\mathrm{N}_{2}$ and air were carried out using a cylindrical furnace that allows the formation of pores in the structures. The inner diameter of the quartz cylinder used in the furnace was $38 \mathrm{~mm}$, and the length was $650 \mathrm{~mm}$. For the Fe-CNHs oxidized in $\mathrm{CO}_{2}-\mathrm{N}_{2}$, the concentration of $\mathrm{CO}_{2}$ was controlled in which $\mathrm{CO}_{2}: \mathrm{N}_{2}$ molar ratio was 1:9 and the total flow rate was adjusted to $300 \mathrm{~cm}^{3} / \mathrm{min}$. The as-grown Fe-CNHs were placed in the furnace before the temperature was raised to $1000{ }^{\circ} \mathrm{C}$ at a steady rate of $7^{\circ} \mathrm{C} \mathrm{min}{ }^{-1}$, and the temperature was kept constant for a varied duration up to $120 \mathrm{~min}$. In the case of the Fe-CNHs oxidized in air, the quartz cylinder was open at its both ends. The furnace temperature was increased from $350{ }^{\circ} \mathrm{C}$ to $450{ }^{\circ} \mathrm{C}$ in accordance to the targeted burn-off percentage of the specimen, and the duration of the oxidation was 30 min for all the oxidations.

The porosity of the Fe-CNHs was analyzed by a volumetric adsorption analyzer (Bel Japan, 
Belsorp-mini) using $\mathrm{N}_{2}$ adsorption at 77 K. A transmission electron microscope (TEM) (JEOL, JEM1010) was used to investigate the structural formation of Fe-CNHs. In addition, the crystal structures of the dispersing nanoparticles in Fe-CNHs were characterized by an X-ray diffractometer (Rigaku, RINT2100) with $\mathrm{CuK \alpha}$ radiation at the power of $40 \mathrm{kV}$ and $40 \mathrm{~mA}$. Furthermore, AC magnetic susceptibility was measured at room temperature by a magnetometer (Magqu Co., XacQuan-II), with maximum magnetic flux of $15 \mathrm{mG}$ and varied frequencies.

\section{Results and discussion}

\subsection{Microscope observation}

The structure of Fe-CNHs was observed by TEM to investigate the influence of the oxidation treatments. TEM images obtained from the Fe-CNHs before oxidation are shown in Fig. 2a and 2b. It is shown here that Fe nanoparticles are dispersed in Fe-CNHs. Fe-CNHs oxidized in $\mathrm{CO}_{2}-\mathrm{N}_{2}$ environment are shown in Fig. 2c. One can notice that the nanoparticles with diameters ranging from 3 to $15 \mathrm{~nm}$ were dispersed in $\mathrm{CNH}$ matrix, and these particles are identified to be ferrimagnetic $\mathrm{Fe}_{3} \mathrm{O}_{4}$ as explained later. In comparison, the TEM images obtained from the nonoxidized Fe-CNHs seemed similar to those from the Fe-CNHs oxidized in $\mathrm{CO}_{2}-\mathrm{N}_{2}$ environment. The Fe-CNHs structures oxidized in $\mathrm{CO}_{2}-\mathrm{N}_{2}$ and the size of $\mathrm{Fe}_{3} \mathrm{O}_{4}$ nanoparticles seemed irrelevant to the oxidation duration, which was extended up to $120 \mathrm{~min}$. It is suggested that the frames of CNHs were not influenced by the oxidation in $\mathrm{CO}_{2}-\mathrm{N}_{2}$ under the present oxidizing conditions.

In contrast to the $\mathrm{CO}_{2}-\mathrm{N}_{2}$ oxidation, the oxidation in air had a significant influence on the Fe-CNH structures. The TEM image in Fig. 2d shows an example that carbonaceous CNHs were removed when undergoing an excessive oxidation treatment. During the oxidation in air, the nanoparticles dispersing in the Fe-CNHs were transformed into paramagnetic $\mathrm{Fe}_{2} \mathrm{O}_{3}$ that tended to be merging with each other, and this will be discussed in details in the subsequent sections.

To evaluate the influence of the oxidation, a burn-off percentage is defined by Eq. 1 as follows. 


$$
B=\left(W_{0}-W_{1}\right) / W_{0} \times 100
$$

where $B[\%], W_{0}[\mathrm{~g}]$, and $W_{1}[\mathrm{~g}]$ are the burn-off percentage, weight of as-grown Fe-CNHs before the oxidation, and weight of Fe-CNHs after oxidation, respectively. Fig. 3 shows the burn-off percentage determined by the $\mathrm{CO}_{2}-\mathrm{N}_{2}$ oxidation as a function of oxidation duration. As displayed in the plots, the burn-off percentage stabilizes at 50\% onwards after 30 min of oxidation, suggesting the stable frames of $\mathrm{CNHs}$ irrelevant to the oxidation in $\mathrm{CO}_{2}-\mathrm{N}_{2}$ under the presented conditions, and only the weak sites on CNHs being replaced by the pores. This finding has a good agreement with the previous report that carbon atoms at non-six-membered rings on CNHs could be lost in mild oxidation environment [11].

In contrast to the oxidations in $\mathrm{CO}_{2}-\mathrm{N}_{2}$, the oxidation conditions in air have demonstrated significant influence on the burn-off percentage of Fe-CNHs. As indicated by Fig. 4, the burn-off percentage increases drastically when Fe-CNHs situated in a more oxidative environment because of a raising temperature. Similar Fe-CNHs structures were observed under TEM as compared to Fig. 2c when the burn-off percentage was below 24\%. However, when the burn-off percentage reached 48\%, carbonaceous CNHs were partially removed as indicated in Fig. 2d. Furthermore, no carbon can be found at $67 \%$ of the burn-off percentage. By comparing the results obtained from the oxidations in $\mathrm{CO}_{2}-\mathrm{N}_{2}$ and air in the range of $48-50 \%$, it should be emphasized that the structural feature of Fe-CNHs can be different after heat treatment of different oxidation conditions, although the burn-off percentages of these oxidized Fe-CNHs are the similar.

Upon the complete removal of carbon by oxidation in air at $1000{ }^{\circ} \mathrm{C}$, the weight of the remaining substance, which was confirmed to be $\mathrm{Fe}_{2} \mathrm{O}_{3}$ by XRD, was measured and used for the calculation of Fe-inclusion percentage in the as-grown Fe-CNHs. As a result, Fe was included in the as-grown Fe-CNHs by 13 wt\%. One may concern about how the production rate can be improved to obtain Fe-CNHs. At this stage, the production rate to obtain Fe-CNHs by the GI- 
AIW method has reached $94 \mathrm{mg} / \mathrm{min}$ under a modified condition with anode outer diameter and hole diameter $=6$ and $2.0 \mathrm{~mm}$, cathode out diameter and hole diameter $=20$ and $12 \mathrm{~mm}$, Fe wire diameter $=1.45 \mathrm{~mm}$, and DC electric current $=100 \mathrm{~A}$. For efficient mass production, the production rate and yield by this method can be further improved by varying electrode size [19], reaction time [22], electrode motion speed [23], gas components [24], electric current [24], gas flow rate [25], and so forth.

\subsection{Porosity analysis by $N_{2}$ adsorption}

The adsorption-desorption isotherms analyzed for the Fe-CNHs oxidized in $\mathrm{CO}_{2}-\mathrm{N}_{2}$ and in air are shown in Fig. 5. The specific surface areas of Fe-CNHs oxidized in $\mathrm{CO}_{2}-\mathrm{N}_{2}$ at varied oxidation durations were calculated by BET method, and the results are plotted in Fig. 6. As can be seen from the plots, the specific surface area was enlarged from $184 \mathrm{~m}^{2} / \mathrm{g}$ to $\sim 500 \mathrm{~m}^{2} / \mathrm{g}$ by the $\mathrm{CO}_{2}-\mathrm{N}_{2}$ oxidation. It should be noted that the specific surface area of Fe-CNHs at the commencement of the oxidation is higher than that of the as-grown Fe-CNHs, because the specimen was oxidized during the time when the furnace temperature was raised from room temperature to $1000{ }^{\circ} \mathrm{C}$, which is about $100 \mathrm{~min}$. The carbon-based specific surface area is determined based on the mass of carbon in the oxidized Fe-CNHs specimen, and this value was enhanced from $224 \mathrm{~m}^{2} / \mathrm{g}$ to $863 \mathrm{~m}^{2} / \mathrm{g}$ by the oxidation in $\mathrm{CO}_{2}-\mathrm{N}_{2}$ at the presented conditions. Compared with CNHs (without Fe) oxidized in $\mathrm{CO}_{2}$ at $1000{ }^{\circ} \mathrm{C}$ previously reported, informing 668-820 $\mathrm{m}^{2} / \mathrm{g}$ [26], our products can have higher carbon-base specific surface area. Furthermore, the specific surface area seemed constant throughout the oxidation duration, implying that the frames of the CNHs remained stable against the oxidizing environment in $\mathrm{CO}_{2}-\mathrm{N}_{2}$.

The specific surface area of Fe-CNHs oxidized in air is plotted as a function of burn-off percentage in Fig. 7. The maximum value of specific surface area can be found at the burn-off percentage of $24 \%$. The increase of the specific surface area in relation to the burn-off percentage at lower range of $0-24 \%$ is due to the opening pores on CNHs, and a reversed tendency found at 
the higher range of burn-off percentage of $24-67 \%$ could be attributed to the removal of carbonaceous CNHs because of excessive oxidation.

Based on the $\mathrm{N}_{2}$ adsorption results, pore volumes in the mesopore range (radii 1.0 - $20 \mathrm{~nm}$ ) were estimated by the method proposed by Dollimore and Heal [27], and the micropore volumes were evaluated by $t$-plot method [28], and the results are summarized in Table 1 . The micropore volume reached to its maximum as the specific surface area at its highest value, corresponding to the burn-off percentage of $24 \%$ in the case of the oxidation in air. Such high value of micropore volume was then reduced drastically by the excessive oxidation. As being stated in the table, the mesopore volume was increased by oxidation, and this relationship is more prominent for the oxidation in $\mathrm{CO}_{2}-\mathrm{N}_{2}$ than in air. The mesopores introduced by oxidation can probably contribute to the inner void at the horn structures, allowing for an improved diffusion of the oxidizing gases to reach the Fe nanoparticles dispersing in CNHs.

Table 1 Pore volumes in Fe-CNHs oxidized in $\mathrm{CO}_{2}$ and in air.

\begin{tabular}{llcccc}
\hline \hline gas species & $\begin{array}{l}\text { temperature } \\
\text { for oxidation }\left[{ }^{\circ} \mathrm{C}\right]\end{array}$ & $\begin{array}{l}\text { duration } \\
\text { for oxidation [min] }\end{array}$ & $\begin{array}{c}\text { burn-off } \\
\text { percentage[\%] }\end{array}$ & $\begin{array}{c}\text { micropore } \\
\text { volume }\left[\mathrm{cm}^{3} / \mathrm{g}\right]\end{array}$ & $\begin{array}{c}\text { mesopore } \\
\text { volume }\left[\mathrm{m}^{3} / \mathrm{g}\right]\end{array}$ \\
\hline$($ as-grown Fe-CNHs) & none & none & 0 & 0.01 & 0.93 \\
$\mathrm{CO}_{2}-\mathrm{N}_{2}$ & 1000 & 60 & 52 & 0.07 & 1.14 \\
$\mathrm{CO}_{2}-\mathrm{N}_{2}$ & 1000 & 120 & 47 & 0.08 & 1.25 \\
air & 400 & 30 & 24 & 0.23 & 1.01 \\
air & 450 & 30 & 67 & 0.14 & 0.98 \\
\hline
\end{tabular}

\subsection{XRD analysis on nanoparticles dispersing in CNHs}

Typical XRD patterns of Fe-CNHs, as shown in Fig. 8, were used to reveal the influence of oxidizing conditions on the crystal structures of nanoparticles dispersing in CNHs. The results from both the as-grown Fe-CNHs and typical Fe-CNHs oxidized in respective $\mathrm{CO}_{2}-\mathrm{N}_{2}$ and air environments have been presented. For reference, the XRD characterization was also performed on the pristine $\mathrm{Fe}, \mathrm{Fe}_{2} \mathrm{O}_{3}$ and $\mathrm{Fe}_{3} \mathrm{O}_{4}$, which were purchased from Nilaco Co. and Wako Chemical Co. It is shown that the Fe nanoparticles in as-grown Fe-CNHs are not oxidized and their metallic 
body-centered cubic (bcc) structure is preserved as indexed by the peak at $44^{\circ}$.

Distinctive structures can be identified for the nanoparticles dispersing in the as-grown FeCNHs, Fe-CNHs oxidized in $\mathrm{CO}_{2}-\mathrm{N}_{2}$, and Fe-CNHs oxidized in air. When Fe-CNHs were oxidized in $\mathrm{CO}_{2}-\mathrm{N}_{2}$, the dispersing nanoparticles were exclusively transformed into ferrimagnetic $\mathrm{Fe}_{3} \mathrm{O}_{4}$. Whereas, when oxidized in air, Fe nanoparticles became paramagnetic $\mathrm{Fe}_{2} \mathrm{O}_{3}$, and no coexisting ferrimagnetic $\mathrm{Fe}_{3} \mathrm{O}_{4}$ can be identified.

Because soot is not formed in the product after the heat treatment in $\mathrm{CO}_{2}-\mathrm{N}_{2}, \mathrm{CO}_{2}$ is not dissociate to $\mathrm{C}$ and $\mathrm{O}_{2}$ there. Then, oxidation in $\mathrm{CO}_{2}-\mathrm{N}_{2}$ should occur by producing $\mathrm{CO}$. The production of CO in oxidation of CNHs is informed by Bekyarova et al. [26] The Gibbs free energy of reaction of $\mathrm{CO}_{2}+2 \mathrm{Fe}_{3} \mathrm{O}_{4}->\mathrm{CO}+3 \mathrm{Fe}_{2} \mathrm{O}_{3}$ is $+62.4 \mathrm{~kJ} / \mathrm{mol}$. (Heat of reaction is +48.5 $\mathrm{kJ} / \mathrm{mol}$.) Thus, oxidation of $\mathrm{Fe}_{3} \mathrm{O}_{4}$ to generate $\mathrm{Fe}_{2} \mathrm{O}_{3}$ by reaction with $\mathrm{CO}_{2}$ may hardly occur thermodynamically.

Fig. 9 shows XRD patterns from the Fe-CNHs oxidized in $\mathrm{CO}_{2}-\mathrm{N}_{2}$ depending on three oxidation durations. The transformation of Fe nanoparticles into $\mathrm{Fe}_{3} \mathrm{O}_{4}$ was found to occur from an early stage of oxidation. The crystal grain sizes estimated by using Scherrer's equation [29] are also displayed in Fig. 9, where a positive correlation between the crystal grain size and oxidation duration can be noted. This relationship is important for the study of magnetic property, which will be presented in the subsequent sections.

Fig. 10 shows XRD patterns from Fe-CNHs oxidized in air with three different burn-off percentages. The Fe nanoparticles dispersing in $\mathrm{CNH}$ s were transformed into $\mathrm{Fe}_{2} \mathrm{O}_{3}$ within a relatively short oxidation duration. The change of Gibbs free energy for reaction of $\mathrm{O}_{2}+4 \mathrm{Fe}_{3} \mathrm{O}_{4}$ $->6 \mathrm{Fe}_{2} \mathrm{O}_{3}$ is $-389.6 \mathrm{~kJ} / \mathrm{mol}$ (Heat of reaction $=-469 \mathrm{~kJ} / \mathrm{mol}$ ), and the transformation of $\mathrm{Fe}_{3} \mathrm{O}_{4}$ to $\mathrm{Fe}_{2} \mathrm{O}_{3}$ by the reaction with $\mathrm{O}_{2}$ can be expected. We should notice that the peaks in XRD pattern at burn-off percentage of $67 \%$ were clearer than those in all the other patterns, which could be a possible result of the complete removal of carbonaceous CNHs and merging nanoparticles at burnoff percentage of $67 \%$. 


\subsection{Magnetic properties}

The as-grown Fe-CNHs and Fe-CNHs oxidized in $\mathrm{CO}_{2}-\mathrm{N}_{2}$ can be collected by applying a magnetic field towing to their ferro- and ferrimagnetic properties of Fe nanoparticles and $\mathrm{Fe}_{3} \mathrm{O}_{4}$ nanoparticles dispersing in CNHs, respectively. The drifting motion of the as-grown Fe-CNHs in ethanol is shown in Fig. 11, and a recorded video can be found available online as a supplementary information of the present article. In this demonstration, the as-grown Fe-CNHs were dispersed in ethanol contained in a polystyrene vial, and the magnetic field was applied externally using a neodymium magnet with a surface magnetic flux of $150 \mathrm{mT}$. A similar drifting motion was observed in other demonstrations when Fe-CNHs oxidized in $\mathrm{CO}_{2}-\mathrm{N}_{2}$ were used.

The AC magnetic susceptibilities of Fe-CNHs oxidized in $\mathrm{CO}_{2}-\mathrm{N}_{2}$ with varied oxidation durations are presented in Fig. 12a, b. The real part $\chi_{\mathrm{R}}$ and imaginary part $\chi_{\mathrm{I}}$ of the complex quantities of the AC magnetic susceptibility as a function of frequency of AC magnetic field are shown in the figures. An important finding is that both $\chi_{\mathrm{R}}$ and $\chi_{\mathrm{I}}$ were increased by oxidation in $\mathrm{CO}_{2}-\mathrm{N}_{2}$ across the entire frequency domain. The values of $\chi_{\mathrm{R}}$ and $\chi_{\mathrm{I}}$ here indicate the degree of magnetization of the materials in response to the AC magnetic field, and are defined by a unit mass of the total structures of Fe-CNHs including carbonaceous $\mathrm{CNHs}$ and $\mathrm{Fe}_{3} \mathrm{O}_{4}$ nanoparticles. This value is meaningful when the magnetic mobility of Fe-CNHs is evaluated in a fluid.

It should be informed that the values of $\chi_{\mathrm{R}}$ and $\chi_{\mathrm{I}}$ could be negligible when the magnetic particles $\mathrm{Fe}_{3} \mathrm{O}_{4}$ were excluded from the $\mathrm{CNHs}$, as confirmed by analysis on pure-carbon CNHs. Therefore, the values of $\chi_{\mathrm{R}}$ and $\chi_{\mathrm{I}}$ in the Fe-CNHs oxidized in $\mathrm{CO}_{2}-\mathrm{N}_{2}$ should be contributed solely by $\mathrm{Fe}_{3} \mathrm{O}_{4}$ nanoparticles. By considering the burn-off percentage, the values of $\chi_{\mathrm{R}}$ per unit mass of $\mathrm{Fe}_{3} \mathrm{O}_{4}$ can be calculated. When Fe-CNHs are driven by a permanent magnet as demonstrated in Fig. 11, the frequency is regarded as $0 \mathrm{~Hz}$. Thus, $\chi_{\mathrm{R}}$ of $0 \mathrm{~Hz}$ susceptibility is of great importance to evaluate the movement of Fe-CNHs driven by a permanent magnet.

The $0 \mathrm{~Hz}$ susceptibility was extrapolated from the relation between $\chi_{\mathrm{R}}$ and the frequency as illustrated in Fig. 12a, and its values per unit mass of $\mathrm{Fe}_{3} \mathrm{O}_{4}$ were calculated and plotted in Fig. 
12c. As seen from the plots, $\chi_{\mathrm{R}}$ of $0 \mathrm{~Hz}$ susceptibility tended to decrease in the duration range of 0-60 min and increase from 60 min onwards. It should be noted that the $\chi_{\mathrm{R}}$ of $0 \mathrm{~Hz}$ susceptibility per unit mass of metallic Fe in the as-grown Fe-CNHs was as high as 208 [(Fe-g) $\left.)^{-1}\right]$. Thus, the tendency to decrease the $\chi_{\mathrm{R}}$ of $0 \mathrm{~Hz}$ susceptibility in the range 0-60 min in Fig. 12c could be a result of the elimination of the contamination of metallic Fe. The increase of the $\chi_{\mathrm{R}}$ in Fig. 12c in the longer oxidation duration range can be explained by the growth of the crystal grain in $\mathrm{Fe}_{3} \mathrm{O}_{4}$ nanoparticles as suggested by Fig. 9 .

The shape of $\chi_{\mathrm{R}}$-frequency relationship also can suggest an information for potential application. It can be seen that the value of $\chi_{\mathrm{R}}$ can keep a relatively high value up to $13000 \mathrm{~Hz}$, and it drops down in the range above this frequency. This result suggests that the product may be effectively useful up to this frequency for some magnetic applications, such as oscillator, electromagnetic wave absorber, etc.

Fig. 13 shows the AC magnetic susceptibilities of Fe-CNHs oxidized in air. In contrast to the oxidation in $\mathrm{CO}_{2}-\mathrm{N}_{2}$, the value of $\chi_{\mathrm{R}}$ and $\chi_{\mathrm{I}}$ were significantly decreased by oxidation treatment, which is a consequence of the paramagnetic $\mathrm{Fe}_{2} \mathrm{O}_{3}$ formation as confirmed by the XRD analysis. It should be noticed that the susceptibility started to decrease even when the burn-off percentage was comparatively low.

\section{Conclusions}

Ferrimagnetic $\mathrm{Fe}_{3} \mathrm{O}_{4}$ nanoparticles belong to a family of useful functional materials that can be driven by a magnetic field. Novel functional materials combining $\mathrm{Fe}_{3} \mathrm{O}_{4}$ nanoparticles and surface-enhanced carbon nanoparticles indicate promising applications in a broad range of research activities. Our study revealed that the Fe-CNHs oxidized in $\mathrm{CO}_{2}-\mathrm{N}_{2}$ possessed enhanced porosity and magnetic susceptibility. In addition, the transformation from Fe nanoparticles dispersed in $\mathrm{CNH}$ s to $\mathrm{Fe}_{3} \mathrm{O}_{4}$ can be considered useful because the formed $\mathrm{Fe}_{3} \mathrm{O}_{4}$ is stable against corrosion. 
As discussed in this paper, the frames of the carbonaceous portion of Fe-CNHs were found stable against the oxidation in $\mathrm{CO}_{2}-\mathrm{N}_{2}$, and therefore, the burn-off percentage stayed below $50 \%$ when the oxidation duration was extended. This stability should contribute to a good preservation of the ferrimagnetic $\mathrm{Fe}_{3} \mathrm{O}_{4}$ nanoparticles dispersed in CNHs. On the other hand, excessive oxidation in air resulted in destructive loss of carbon, and Fe nanoparticles easily became paramagnetic $\mathrm{Fe}_{2} \mathrm{O}_{3}$ in such a condition. In future, the application study of Fe-CNHs will be worthy utilizing their characteristics of magnetic drivability and high surface area.

\section{Acknowledgement}

This work was financially supported by JSPS KAKENHI Grant Number 24360327.

\section{References}

[1] Q. Cao, S.-J. Han, G.-S. Tulevski, Y. Zhu, D. D. Lu, W. Haensch, Arrays of single-walled carbon nanotubes with full surface coverage for high-performance electronics, Nature Nanotechnol. 8 (2013) 180-186.

[2] L. Ding, S. Liang, T. Pei, Z. Zhang, S. Wang, W. Zhou, J. Liu, L. M. Peng, Carbon nanotube based ultra-low voltage integrated circuits: Scaling down to 0.4 V, Appl. Phys. Lett. 100 (2012) 263116.

[3] A. S. Wu, X, Nie, M. C. Hudspeth, W. W. Chen, T.-W. Chou, D. S. Lashmore, M. W. Schauer, E. Towle, J. Rioux, Carbon nanotube fibers as torsion sensors, Appl. Phys. Lett. 100 (2012) 201908.

[4] T. Yamada, Y. Hayamizu, Y. Yamamoto, Y. Yomogida, A. Izadi-Najafabadi, D. N. Futaba, et al. A stretchable carbon nanotube strain sensor for human-motion detection, Nature Nanotechnol. 6 (2011) 296-301.

[5] A. A. S. Oliveira, I. F. Teixeira, L. P. Ribeiro, J. C. Tristao, A. Dias, R. M. Lago, Magnetic amphiphilic composites based on carbon nanotubes and nanofibers grown on an inorganic 
matrix: Effect on water-oil interfaces, J. Braz. Chem. Soc. 21 (2010) 2184-2188.

[6] S. Takenaka, T. Tsukamoto, H. Matsunea, M. Kishida, Carbon nanotube-supported Pd-Co catalysts covered with silica layers as active and stable cathode catalysts for polymer electrolyte fuel cells, Catal. Sci, Technol. 3 (2013) 2723-2731.

[7] A. Nikitin, X, Li, Z. Zhang, H. Ogasawara, H. Dai, A. Nilsson, Hydrogen storage in carbon nanotubes through the formation of stable C-H bonds. Nano. Lett. 8 (2008) 162-167.

[8] M. Delavar, A. A. Ghoreyshi, M. Jahanshahi, S. Khalili, N. Nabian, Equilibria and kinetics of natural gas adsorption on multi-walled carbon nanotube material, RSC Adv. 2 (2012) 44904497.

[9] S. Iijima, M. Yudasaka, R. Yamada, S. Bandow, K. Suenaga, F. Kokai, et al. Nano-aggregates of single-walled graphitic carbon nano-horns, Chem. Phys. Lett. 309 (1999) 165-170.

[10]E. Bekyarova, K. Murata, M. Yudasaka, D. Kasuya, S. Iijima, H. Tanaka, et al. Single-wall nanostructured carbon for methane storage, J. Phys. Chem. B 107 (2003) 4681-4684.

[11] S. Utsumi, J. Miyawaki, H. Tanaka, Y. Hattori, T. Itoi, N. Ichikuni, et al. Opening mechanism of internal nanoporosity of single-wall carbon nanohorn, J. Phys. Chem. B 109 (2005) 1431914124.

[12] T. Murakami, K. Ajima, J. Miyawaki, M. Yudasaka, S. Iijima, K. Shiba. Drug-loaded carbon nanohorns: adsorption and release of dexamethasone in vitro, Mol. Pharm. 1 (2004) 399-405.

[13] K. Kobayashi, T. Shimazu, Y. Yamada, A. Koshio, Y. Takahashi, F. Kokai, Formation of single-wall carbon nanohorn aggregates hybridized with carbon nanocapsules by laser vaporization, Appl. Phys. A 89 (2007) 121-126.

[14] F. Kokai, K. Takahashi, D. Kasuya, M. Yudasaka, S. Iijima, Growth dynamics of single-wall carbon nanotubes and nanohorn aggregates by $\mathrm{CO}_{2}$ laser vaporization at room temperature, Appl. Surf. Sci. 197-198 (2002) 650-655.

[15] H. Takikawa, M. Ikeda, K. Hirahara, Y. Hibi, Y. Tao, P. A. Ruiz Jr, et al. Fabrication of singlewalled carbon nanotubes and nanohorns by means of a torch arc in open air, Physica B 323 
(2002) 277-279.

[16] M. Ikeda, H. Takikawa, T. Tahara, Y. Fujimura, M. Kato, K. Tanaka, et al. Preparation of carbon nanohorn aggregates by cavity arc jet in open air, Jpn. J. Appl. Phys. 41 (2002) L852L854.

[17] T. Yamaguchi, S. Bandow, S. Iijima, Synthesis of carbon nanohorn particles by simple pulsed arc discharge ignited between pre-heated carbon rods, Chem. Phys. Lett. 389 (2004) : 181-185.

[18] N. Sano, Low-cost synthesis of single-walled carbon nanohorns using the arc in water method with gas injection, J. Phys. D: Appl. Phys. 37 (2004) L17-L20.

[19] N. Sano, Y. Akita, H. Tamon, Effects of synthesis conditions on the structural features and methane adsorption properties of single-walled carbon nanohorns prepared by a gas-injected arc-in-water method, J. Appl. Phys. 109 (2011) 124305.

[20] N. Sano, T. Ishii, H. Mori, Y. Ikeyama, H. Tamon, One-step synthesis of single-walled carbon nanohorns dispersed with Pd-Ni alloy nanoparticles by gas-injected arc-in-water method and effects of synthesis factors on their hydrogen sensor sensitivity, J. Appl. Phys. 112 (2012) 044301.

[21] C. Poonjarernsilp, N. Sano, T. Charinpanitkul, H. Mori, T. Kikuchi, H. Tamon, Single-step synthesis and characterization of single-walled carbon nanohorns hybridized with Pd nanoparticles using N2 gas-injected arc-in-water method, Carbon 49 (2011) 4920-4927.

[22] N. Sano, T. Suzuki, K. Hirano, Y. Akita, H. Tamon, Influence of arc duration time on the synthesis of carbon nanohorns by a gas-injected arc-in-water system: application to polymer electrolyte fuel cell electrodes, Plasma Sources Sci. Technol. 20 (2011) 034002.

[23] N. Sano, Y. Yasumura, Y. Kimura, A. Toyoda, K. Hirano, Low-cost synthesis of carbon nanohorns by nitrogen-injected arc-in-water system, use of low purity electrode for high yield production, Trans. Mat. Res. Soc. Jpn. 33 (2008) 669-672.

[24] N. Sano, Y. Kimura, T. Suzuki, Synthesis of carbon nanohorns by a gas-injected arc-in-water method and application to catalyst-support for polymer electrolyte fuel cell electrodes, J. Mater. 
Chem. 18 (2008) 1555-1560.

[25] N. Sano, K. Taniguchi, H. Tamon, Gas flow rate in the gas-injected arc-in-water method as a critical factor to synthesize high-dispersion Pd-Ni alloy nanoparticles in single-walled carbon nanohorns, J. Chem. Eng. Jpn. 47 (2014) 821-826.

[26] E. Bekyarova, K. Kaneko, M. Yudasaka, D. Kasuya, S. Iijima, A. Huidobro, and R-R Francisco, Controlled opening of single-wall carbon nanohorns by heat treatment in carbon dioxide, J. Phys. Chem. B 107 (2003) 4479-4484.

[27] D. Dollimore, G. R. Heal, An improved method for the calculation of pore size distribution from adsorption data, J. Appl. Chem. 14 (1964) 109-114.

[28] B. C. Lippens, J. H. de Boer, Studies on pore systems in catalysts: V. The t method, J. Catal. 4 (1965) 319-323.

[29] P. Scherrer, Bestimmung der Größe und der inneren Struktur von Kolloidteilchen mittels Röntgenstrahlen, Nachr Ges Wiss Göttingen 26 (1918) 98-100.

\section{Figure captions}

Fig. 1. Structures and dimensions of electrodes in GI-AIW method to synthesize Fe-CNHs.

Fig. 2. TEM images of the Fe-CNHs (a) before oxidation in low magnification, (b) in high magnification, (c) after oxidation in $\mathrm{CO}_{2}-\mathrm{N}_{2}$ at $1000{ }^{\circ} \mathrm{C}$ for $60 \mathrm{~min}$, and (d) in air at $425{ }^{\circ} \mathrm{C}$ for $30 \mathrm{~min}$.

Fig. 3. Burn-off percentages of Fe-CNHs by oxidation in $\mathrm{CO}_{2}-\mathrm{N}_{2}$ with varied oxidation durations at $1000^{\circ} \mathrm{C}$.

Fig. 4. Burn-off percentages of Fe-CNHs oxidized in air at different oxidizing temperatures, where the duration was $30 \mathrm{~min}$.

Fig. 5. Adsorption-desorption isotherms of (a) Fe-CNHs oxidized in $\mathrm{CO}_{2}-\mathrm{N}_{2}$ at $1000{ }^{\circ} \mathrm{C}$ for varied durations, and (b) in air at varied oxidation temperatures for 30 min duration. Open and solid symbols correspond to adsorption and desorption, respectively. 
Fig. 6. Specific surface areas of Fe-CNHs oxidized in $\mathrm{CO}_{2}-\mathrm{N}_{2}$ at $1000{ }^{\circ} \mathrm{C}$ as a function of oxidation duration.

Fig. 7. Specific surface areas of Fe-CNHs oxidized in air at varied oxidation temperatures for 30 min as a function of burn-off percentage. Refer to Fig. 4 for the oxidation temperatures.

Fig. 8. XRD patterns of as-grown Fe-CNHs, and typical Fe-CNHs oxidized in $\mathrm{CO}_{2}-\mathrm{N}_{2}\left(1000{ }^{\circ} \mathrm{C}\right.$, $60 \mathrm{~min})$ and in air $\left(450{ }^{\circ} \mathrm{C}, 30 \mathrm{~min}\right)$ in comparison with those of pristine $\mathrm{Fe}, \mathrm{Fe}_{2} \mathrm{O}_{3}$, and $\mathrm{Fe}_{3} \mathrm{O}_{4}$ as a reference.

Fig. 9. Influence of oxidation duration on XRD patterns of Fe-CNHs oxidized in $\mathrm{CO}_{2}-\mathrm{N}_{2}$ at $1000{ }^{\circ} \mathrm{C}$. The values of $D$ are crystal grain sizes estimated by Scherrer's equation from the peak at $43.3^{\circ}$.

Fig. 10. XRD patterns showing the influence of oxidation temperature of Fe-CNHs oxidized in air for 30 min. The values of $B$ are burn-off percentages.

Fig. 11. The drifting motion of powdery Fe-CNHs in ethanol inducted by a permanent magnet with a surface magnetic flux of $150 \mathrm{mT}$ (enhanced online).

Fig. 12. AC magnetic susceptibilities of Fe-CNHs oxidized in $\mathrm{CO}_{2}-\mathrm{N}_{2}$ at $1000{ }^{\circ} \mathrm{C}$ concerning oxidation durations. (a) Real part of the complex quantity of AC magnetic susceptibility. (b) Imaginary part of the complex quantity of AC magnetic susceptibility. (c) Real part of $0 \mathrm{~Hz}$ susceptibility as a function of oxidation duration.

Fig. 13. AC magnetic susceptibilities of Fe-CNHs oxidized in air at varied burn-off percentages prepared by changing the corresponding oxidation temperature. (a) Real part of complex AC magnetic susceptibility. (b) Imaginary part of complex AC magnetic susceptibility. 


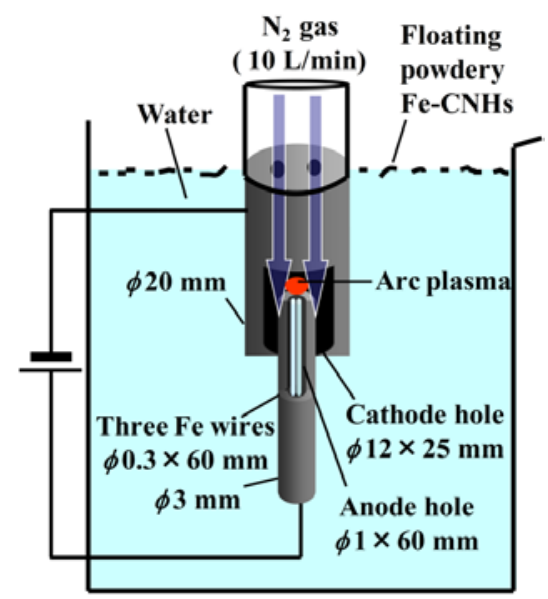

Fig. 1. Structures and dimensions of electrodes in GI-AIW method to synthesize Fe-CNHs.

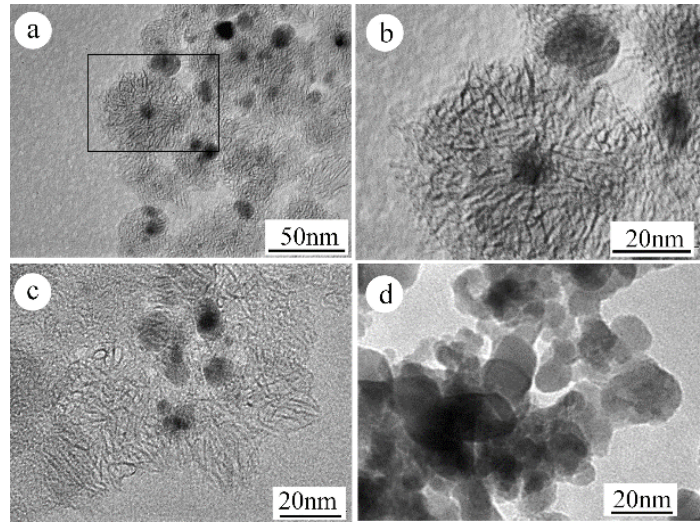

Fig. 2. TEM images of the Fe-CNHs (a) before oxidation in low magnification, (b) in high magnification, (c) after oxidation in $\mathrm{CO}_{2}-\mathrm{N}_{2}$ at $1000{ }^{\circ} \mathrm{C}$ for $60 \mathrm{~min}$, and (d) in air at $425{ }^{\circ} \mathrm{C}$ for $30 \mathrm{~min}$.

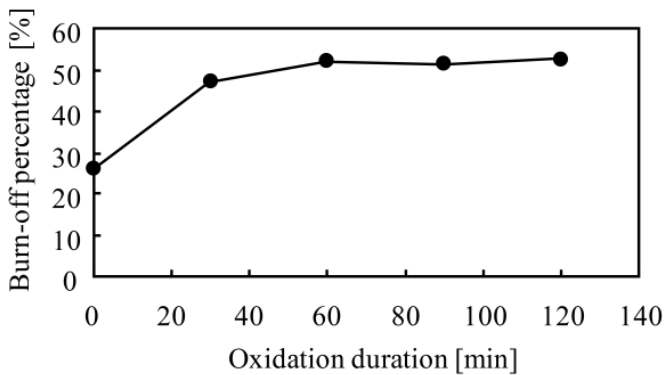

Fig. 3. Burn-off percentages of Fe-CNHs by oxidation in $\mathrm{CO}_{2}-\mathrm{N}_{2}$ with varied oxidation durations at $1000^{\circ} \mathrm{C}$. 


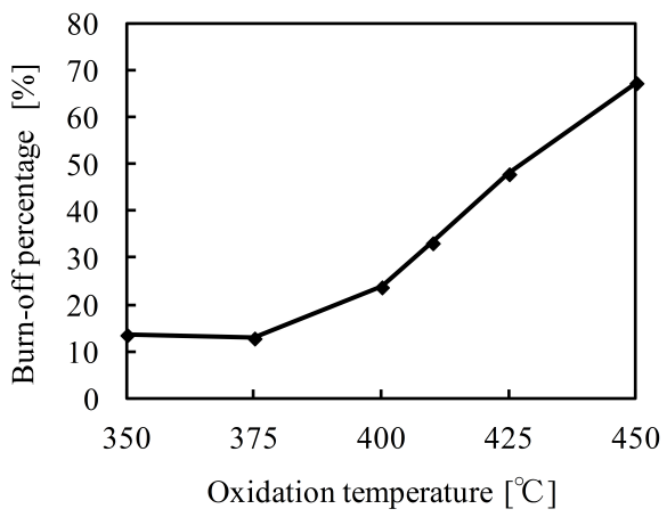

Fig. 4. Burn-off percentages of Fe-CNHs oxidized in air at different oxidizing temperatures, where the duration was $30 \mathrm{~min}$.
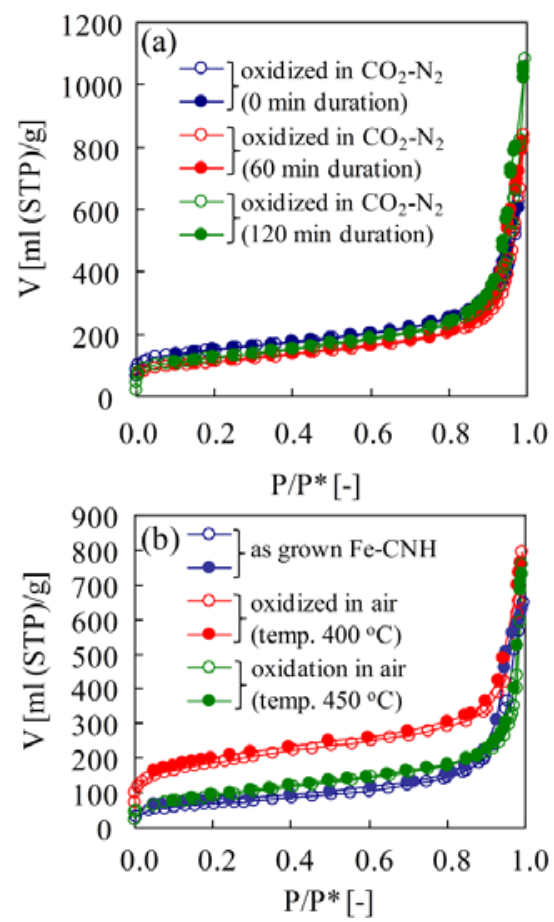

Fig. 5. Adsorption-desorption isotherms of (a) Fe-CNHs oxidized in $\mathrm{CO}_{2}-\mathrm{N}_{2}$ at $1000{ }^{\circ} \mathrm{C}$ for varied durations, and (b) in air at varied oxidation temperatures for 30 min duration. Open and solid symbols correspond to adsorption and desorption, respectively. 


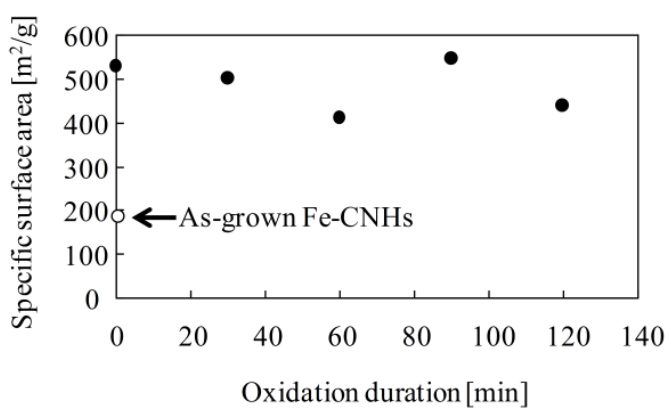

Fig. 6. Specific surface areas of Fe-CNHs oxidized in $\mathrm{CO}_{2}-\mathrm{N}_{2}$ at $1000{ }^{\circ} \mathrm{C}$ as a function of oxidation duration.

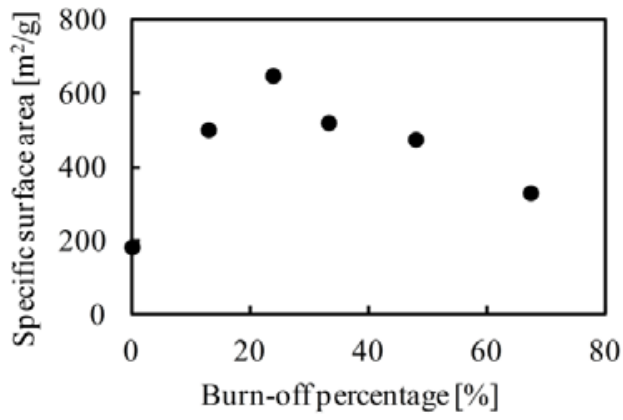

Fig. 7. Specific surface areas of Fe-CNHs oxidized in air at varied oxidation temperatures for 30 min as a function of burn-off percentage. Refer to Fig. 4 for the oxidation temperatures.

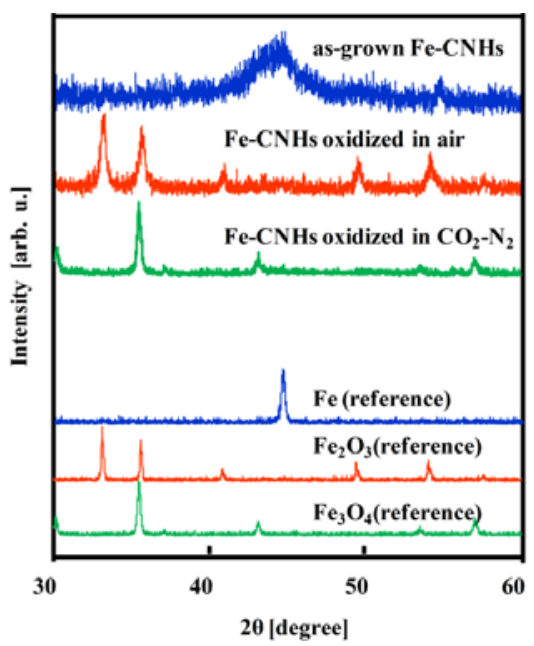

Fig. 8. XRD patterns of as-grown Fe-CNHs, and typical Fe-CNHs oxidized in $\mathrm{CO}_{2}-\mathrm{N}_{2}\left(1000{ }^{\circ} \mathrm{C}\right.$, $60 \mathrm{~min})$ and in air $\left(450{ }^{\circ} \mathrm{C}, 30 \mathrm{~min}\right)$ in comparison with those of pristine $\mathrm{Fe}, \mathrm{Fe}_{2} \mathrm{O}_{3}$, and $\mathrm{Fe}_{3} \mathrm{O}_{4}$ as a reference. 


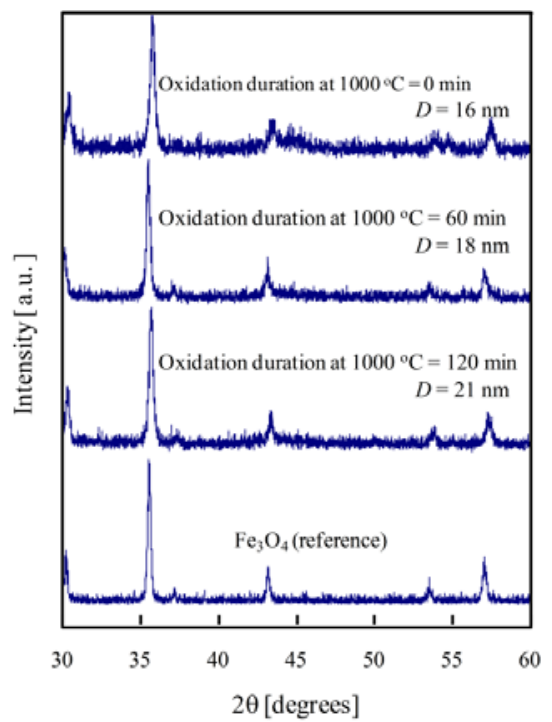

Fig. 9. Influence of oxidation duration on XRD patterns of Fe-CNHs oxidized in $\mathrm{CO}_{2}-\mathrm{N}_{2}$ at $100{ }^{\circ} \mathrm{C}$. The values of $D$ are crystal grain sizes estimated by Scherrer's equation from the peak at $43.3^{\circ}$.

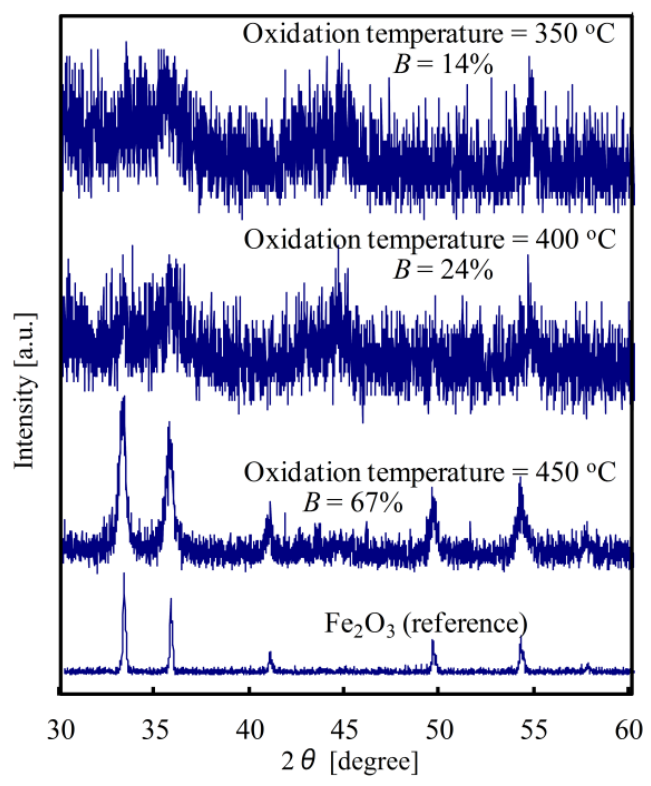

Fig. 10. XRD patterns showing the influence of oxidation temperature of Fe-CNHs oxidized in air for $30 \mathrm{~min}$. The values of $B$ are burn-off percentages. 


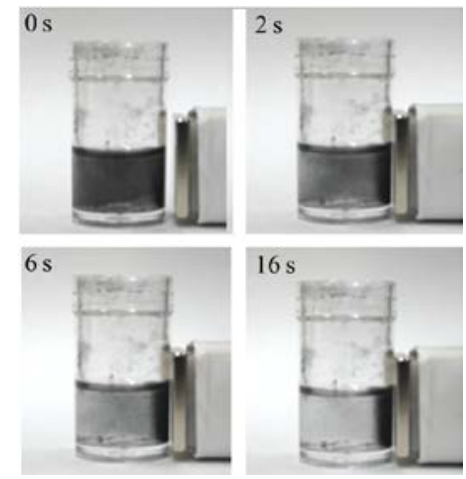

Fig. 11. The drifting motion of powdery Fe-CNHs in ethanol inducted by a permanent magnet with a surface magnetic flux of $150 \mathrm{mT}$ (enhanced online).
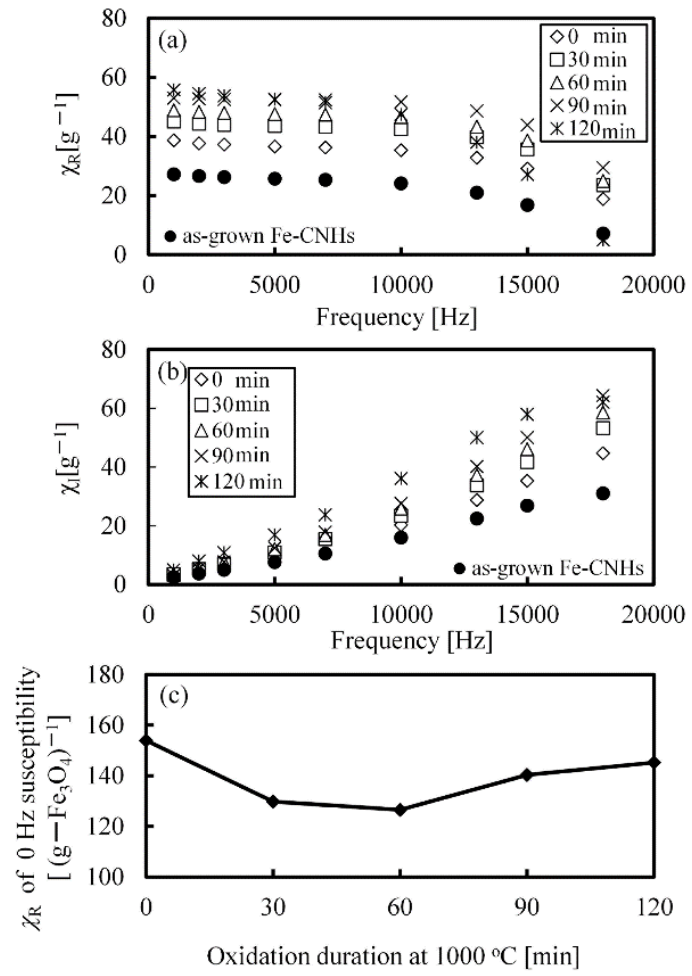

Fig. 12. AC magnetic susceptibilities of Fe-CNHs oxidized in $\mathrm{CO}_{2}-\mathrm{N}_{2}$ at $1000{ }^{\circ} \mathrm{C}$ concerning oxidation durations. (a) Real part of the complex quantity of AC magnetic susceptibility. (b) Imaginary part of the complex quantity of AC magnetic susceptibility. (c) Real part of $0 \mathrm{~Hz}$ susceptibility as a function of oxidation duration. 

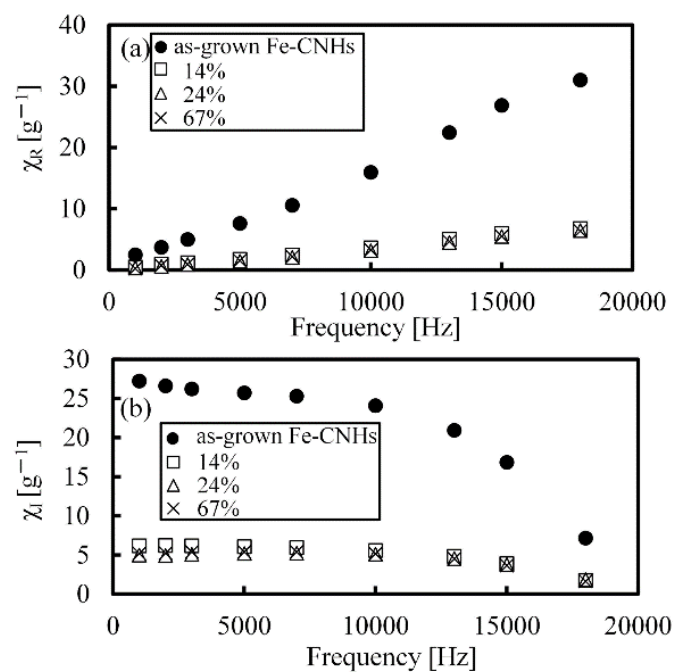

Fig. 13. AC magnetic susceptibilities of Fe-CNHs oxidized in air at varied burn-off percentages prepared by changing the corresponding oxidation temperature. (a) Real part of complex AC magnetic susceptibility. (b) Imaginary part of complex AC magnetic susceptibility. 